Economía, Sociedad y Territorio, vol. vIII, núm. 26, 2008, 313-356

\title{
Hacia un modelo teórico-metodológico para el análisis del desarrollo, la sostenibilidad y el turismo
}

\author{
Rocío del Carmen Serrano-Barquín*
}

\begin{abstract}
In this paper we propose a theoretical-methodological framework linking development and sustainability as well as socio-economical activities such as tourism. The aim is to introduce a model for local development planning that favours an adequate usage of natural and cultural resources for the benefit of the community. This proposal is based on the theory of complex systems and complex thought in order to explain environmental issues. From this analysis we draw the following categories: harmonic tourism, integrating participative planning, environmentally intuitivel rational exploitation and hommo-ecosistem.
\end{abstract}

Keywords: local and sustainable development, sustainable tourism, participative planning, theory of complex systems.

\section{Resumen}

En este artículo se presenta una propuesta teórico-metodológica que vincula el desarrollo, la sostenibilidad y las actividades sociales y económicas con el turismo. El objetivo es proponer un modelo de planeación de desarrollo local que propicie el uso adecuado de los recursos naturales y culturales para beneficio de la comunidad. La propuesta se fundamenta en la teoría de sistemas complejos y el pensamiento complejo para explicar la problemática ambiental. A partir de este análisis se proponen las categorías: turismo armónico, planeación integrativa participante, aprovechamiento ambientalmente intuitivo-racional y hommoecosistema.

Palabras clave: desarrollo local y sostenible, turismo sustentable, planeación participativa, teoría de sistemas complejos.

*Universidad Autónoma del Estado de México. Correo-e: rocioserba@yahoo.com. mxyrcsb@uaemex.mx 


\section{Introducción}

A más de 30 años de que se iniciara formalmente la discusión sobre los problemas ambientales y los esfuerzos para resolverlos, ${ }^{1}$ se observa que dicha problemática, lejos de resolverse, se ha agravado hasta alcanzar niveles críticos en ciertas áreas del planeta y en aspectos de carácter global. ${ }^{2}$ Ante esta situación, una propuesta que ha generado mayor conciencia y apoyo de los diferentes sectores de la sociedad es el desarrollo sostenible, a partir de la publicación del Informe Brundtland en 1987 (Fundación Ebert, s.f.). No obstante, prevalece la discusión acerca de cómo utilizar un concepto tan abstracto y que implica relacionar aspectos naturales y socioeconómicos. Por ello, es prioritario realizar investigaciones que permitan aplicar la sostenibilidad en los diversos ámbitos de la actividad humana (Barkin, 1998; Leff, 2000; Masera et al., 1999; Gliessman, 2002; Tetreault, 2004), superando la visión disciplinaria en favor de una visión holística, sin ignorar todo lo demás, es decir, el entorno del fenómeno estudiado. ${ }^{3}$

Por otro lado, el turismo se considera un instrumento para alcanzar el desarrollo de regiones mediante el impulso de su economía y, en los últimos años, para sacar de la pobreza a comunidades que han permanecido marginadas históricamente, como lo manifiesta la Organización Mundial del Turismo (OMT o wTO, por sus siglas en inglés) en diversos documentos (WTO, 2002; Harris et al., 2003; OMT, 2002) y, por supuesto, la sostenibilidad se ha incorporado a esta actividad, así como la dificultad de su aplicación (Hunter, 2003; Farrell y Twining-Ward, 2004; Barkin, 2000; Hughes, 2002); incluso se han publicado numerosas guías metodológicas para elaborar proyectos turísticos y se han desarrollado indicadores que evalúan los efectos del turismo para

${ }^{1}$ Con la Conferencia de Estocolmo en 1972 y el Programa de las Naciones Unidas para el Medio Ambiente (UNEP o PNUMA), se comienzan a realizar innumerables acciones encaminadas a su solución.

${ }^{2}$ Basta revisar el informe de la UNEP (2002) para confirmar la gravedad del estado del medio ambiente: adelgazamiento de la capa de ozono, a pesar del Protocolo de Kyoto y otros convenios; cambio climático (aumento de entre $1^{\circ} \mathrm{C}$ y $3.5^{\circ} \mathrm{C}$ ) por tala inmoderada, uso de combustibles fósiles y acumulación de $\mathrm{CO}_{2}$; desertificación y erosión, $25 \%$ y $15 \%$, respectivamente, de la superficie de tierras; insuficiencia de agua potable ( $20 \%$ de la población); efectos de la urbanización en la salud de la población; lluvia ácida, entre otros muchos asuntos.

${ }^{3}$ Como señala Gliessman (2002), está claramente definido el concepto de agroecosistema sostenible (o, en general, cualquier sistema sostenible), pero se dificulta llevarlo a la práctica y, más aún, diseñar o construir un sistema sostenible en una región específica. "La sostenibilidad es en última instancia una prueba de tiempo [...] la sostenibilidad se encuentra siempre en el futuro" (p. 303). 
garantizar la sostenibilidad (OMT, 1999a y 1999b; wTO, 1994; Jinyang et al., 2002; Blàzquez, 2002 y 2003; Sectur, 2000 y 2004; Semarnat, 2003). Pero la mayoría de estos indicadores se construyeron y aplicaron en países desarrollados, donde las características del medio natural y las condiciones socioeconómicas, políticas y culturales son muy diferentes a las de los países en desarrollo, como el caso de México. Si bien se conocen casos exitosos, en general se observa que -a pesar de que se logra un importante crecimiento económico en las regiones donde se desarrollan diversos proyectos turísticos- los efectos en la población local no siempre son tan positivos como se plantea originalmente, tanto en aspectos sociales y económicos como en la preservación de los recursos (García, 1979; ${ }^{4}$ Osorio, 1994; Aguilar, 1994; Brenner, 1999; Chávez, 2001; Barkin, 2001; Gallegos y López, 2004).

En este contexto, el presente artículo corresponde a los avances de la propuesta teórico-metodológica elaborada en la investigación "Desarrollo, sostenibilidad y turismo en una comunidad lacustre del Valle de Toluca; caso: San Miguel Almaya, Estado de México" (Serrano, 2006), la cual se llevó a cabo dentro del programa de doctorado en ciencias ambientales de la Universidad Autónoma del Estado de México (UAEM). Con este proyecto se pretende contribuir a la construcción de un marco teóricometodológico alternativo que permita diseñar un modelo de planeación de desarrollo local a partir de proyectos turísticos en comunidades rurales, considerando su entorno regional. Se parte de aceptar que en la problemática ambiental se entrelazan hechos y fenómenos culturales y naturales, donde se considera al ambiente como una totalidad interdependiente en la que se incorporan la incertidumbre, la inestabilidad, las variaciones y la irreversibilidad en el proceso evolutivo del mismo. Metodológicamente se sustenta en la complejidad, la sostenibilidad y los sistemas complejos, lo que permitió crear las siguientes categorías de análisis: aprovechamiento ambientalmente intuitivo-racional, hommoecosistema, planeación integrativa participante y turismo armónico.

\footnotetext{
${ }^{4}$ Uno de los primeros y más importantes estudios que analizan los efectos negativos de la actividad turística en la población receptora es el trabajo de Ana García en Cancún, México. Investigaciones posteriores confirman de una u otra manera que el turismo no sólo genera recursos económicos, también propicia desigualdad y pobreza en las zonas turísticas del país.
} 
El artículo se organiza en dos apartados, además de la introducción y las conclusiones. En el primero se justifica la necesidad de proponer marcos teórico-metodológicos para explicar la problemática ambiental, reconociendo que la sociedad contemporánea transita hacia una etapa de cambios y desarrollo de nuevos paradigmas: la posmodernidad. En el segundo apartado se comentan algunas limitaciones del paradigma dominante, la ciencia positiva, para explicar y solucionar los problemas ambientales y exponer la propuesta que presento para su análisis y discusión.

\section{De la modernidad a la posmodernidad, continuidad o transición}

Históricamente se han presentado diversas propuestas que pretenden conocer y explicar la realidad, pero como señala Wallerstein (1997), la complejidad de los problemas que enfrenta la sociedad actual -entre ellos los ambientales- exige enfoques creativos y multi e interdisciplinarios que requieren nuevos paradigmas, como lo indicó Kuhn (1971) desde la década de los sesenta y que se sigue planteando en la actualidad (Leff, 1994, 2000 y 2002; Prigogine, 1983, 1998a, 1998b y 1998c). Como señala Enrique Leff:

La problemática ambiental plantea la necesidad de internalizar un saber ambiental emergente en todo un conjunto de disciplinas, tanto de las ciencias naturales como sociales, para construir un conocimiento capaz de captar la multicausalidad y las relaciones de interdependencia de los procesos de orden natural y social que determinan cambios socioambientales, así como para construir un saber y una racionalidad social orientados hacia objetivos de un desarrollo sostenible, equitativo y duradero (1994: 17).

Por ello es conveniente reconocer que la sociedad transita por una etapa de cambios y ruptura de paradigmas, en donde también se reconocen otras formas de comprender la realidad. Es el paso de la modernidad a la posmodernidad.

De acuerdo con Ramírez (2003), el periodo de posmodernidad -que también se conoce como de globalización-implica abandonar las promesas de cambio y expectativas de futuro propias de la modernidad, para ubicarse en una etapa de reestructuración de los paradigmas de desarrollo. Para hablar de posmodernidad primero es necesario entender la modernidad. Referirse a los conceptos de modernidad y desarrollo conlleva, sin lugar a dudas, a la reflexión sobre la forma en que la sociedad contem- 
pló su propia evolución, transformación y expectativas (Vattimo, 1990). La palabra moderno se utilizó para distinguir el presente, es un concepto que expresa una y otra vez la conciencia de una época que se relaciona con el pasado. La modernidad se presenta como un continum sociohistórico que tiene diversas interpretaciones y resignificaciones de sentido, por lo que es necesario revisar y analizar los conceptos fundamentales, así como identificar las causas y los efectos de las políticas de modernización como proceso geopolítico y su inclusión en el fenómeno posmoderno. La modernidad es un tiempo de la historia social concebida como una transformación que tiene lugar en los siglos XIX y XX y responde al deseo de alejarse de lo antiguo. Para otros, su origen se remonta al momento del Renacimiento, incluso, autores como Martínez (1997) ubican el inicio de la etapa moderna en las postrimerías del siglo $\mathrm{v}$, cuando se acepta oficialmente al cristianismo y se deja en el pasado el paganismo romano.

Políticamente hablando, la modernidad se percibe desde diferentes perspectivas: a partir del surgimiento de las revoluciones burguesas liberales o de la economía política marxista. Existe, asimismo, una posición filosófica para entenderla como un medio que permite al ser humano liberarse del esoterismo a través del desarrollo de sus potenciales culturales y de una ciencia, moralidad, leyes universales y arte autónomo acordes con su individualidad y lógica interna. Weber definía a la modernidad por la intelectualización y ruptura con el espíritu religioso (en Touraine, 1994). La ideología occidental y la idea de modernidad reemplazaron a Dios por la ciencia. Esta perspectiva se sustenta en dos ideas fundamentales: la primera sostiene que el progreso es una condición a la que se puede aspirar de forma permanente, en tanto la humanidad tenga la capacidad de mejorar indefinidamente en la medida en que logra conocer las leyes que rigen a la naturaleza y a la vida humana en los ámbitos individual y colectivo; la segunda se basa en la premisa de una realidad objetiva analizada a partir de una hipótesis, la cual se comprueba o rechaza a través de la experimentación. Como señala Touraine (1994), la modernidad se asocia con la racionalización característica del pensamiento occidental. También se le considera como un proceso en el que la sociedad busca actualizarse; dicho proceso, calificado como cultural, estaría fuertemente ligado a la organización técnico-científica y sus avances. Según esta perspectiva, el inicio de la modernidad se encontraría en el siglo XVIII, con el surgimiento de la Revolución industrial y el capitalismo. 
Así, este último se considera la expresión económica de la ideología occidental de la modernidad. En este sentido se vincula a la modernidad con el desarrollo de la ciencia y la tecnología desde el punto de vista político-cultural, puesto que se ve en el industrialismo una alternativa para alcanzar la modernidad (desarrollo) y dejar atrás el subdesarrollo. Este pensamiento se refleja en la forma de conocer y explicar la realidad, y se asumía que sólo era posible a través de la ciencia.

Wallerstein (1997) menciona que, como resultado de todas estas transformaciones, el conocimiento se dividió en científico (verdadero y cierto) y no científico (imaginado). En este contexto, la universidad -de corte napoleónico- resurge como la instancia que permite acceder y generar conocimiento a través del método científico. Para ello se divide la realidad y surgen las diversas disciplinas. El propósito de la ciencia es descubrir la realidad objetiva a través del método científico que permite observarla y explicarla. Este conocimiento también se enfocó a mejorar las formas de aprovechar ${ }^{5}$ los recursos naturales, por supuesto, desde la racionalidad económica capitalista que busca obtener las mayores ganancias a corto plazo y con el menor costo; sin importar la degradación de la naturaleza y del ser humano. Así, se favorece la extracción desmedida de recursos naturales, desde el petróleo, el carbón y otros minerales, hasta los bosques y diversas especies de plantas y animales, lo que provoca el deterioro del ambiente. Como se señaló en la Cumbre de la Tierra en Río de Janeiro en 1992, "el medio ambiente mundial continúa deteriorándose y los problemas ambientales importantes siguen todavía profundamente arraigados en el sistema socioeconómico de las naciones, en todas las regiones" (Semarnap-INEGI, 1998: 3) y, que, sin mayores cambios, fue ratificada en la reunión de Johannesburgo en 2002, situación que puede consultarse en los informes periódicos del Programa de las Naciones Unidas para el Medio Ambiente (PNUMA) que contienen datos mundiales; para México, en la Semarnap y otras organizaciones. ${ }^{6}$

\footnotetext{
${ }^{5}$ Aunque podría decirse de expoliación de los recursos y, en general, la degradación del ambiente, pues basta con observar a nuestro alrededor para constatar la destrucción de zonas boscosas (El Nevado de Toluca, La Marquesa), la contaminación de ríos (Lerma), la desaparición o disminución de caudales de manantiales y superficie de cuerpos de agua (Texcaltenco, Alta Empresa y las lagunas del Lerma) y, con estas alteraciones, la desaparición o disminución de especies de flora y fauna (el perro de agua, varias especies de patos, venados, coyotes y demás animales propios de las zonas lacustres y boscosas del Valle de Toluca), las comunidades ribereñas se empobrecen, se modifica su dieta alimenticia y su salud se deteriora.
} 
De esta manera, el supuesto objetivo de la modernidad era construir un mundo diferente basado en la igualdad entre los seres humanos y la necesidad de crear un mundo homogéneo donde no existieran diferencias entre las naciones, lo cual implicaría una integración de sociedades y territorios para lograr que todos los seres humanos se beneficiaran de los resultados de la modernización capitalista. Para conseguirlo, en América Latina se utilizó la planificación como instrumento de política de Estado y se elaboraron innumerables planes, programas y proyectos de desarrollo que contaron con el apoyo de instituciones y organismos internacionales. Así, el capitalismo -como modelo económico distintivo de la modernidad-se implantó en dicha región con rezago respecto de los países del norte, porque, entre otras razones, se pensaba que transitarían por las mismas etapas que atravesaron esos países, sólo que se les olvidó que las naciones desarrolladas apuntalaron su riqueza en la explotación que, históricamente, han hecho de las no desarrolladas. ${ }^{7}$

Pero la modernidad también promovió las luchas sociales, más que establecer los mecanismos para que la nueva sociedad funcionara de acuerdo con esos principios o deseos (Touraine, 1994). Esta ideología, basada en la razón, el placer y el gusto, ignoró los conflictos internos de la sociedad y los interpretó como una reacción irracional al sentido de la razón. Fracasó en su intento por llevar a la Humanidad al desarrollo, al menos no a las mayorías, pues no se puede negar que hay países y sectores de la sociedad que alcanzaron estándares de calidad de vida bastante elevados, pero coexisten con grupos que viven en condiciones extremadamente difíciles. Si bien se presenta crecimiento económico, también se propicia la diferenciación social y la diversidad entre sociedades y países que se revela en la existencia de pueblos sometidos por otros. Así, los ideales de progreso generalizado basado en la igualdad de los seres humanos y los demás principios de la modernidad no se han cumplido. Una característica de las últimas décadas es la presencia de continuas crisis que dificultan el estudio de los hechos, pero lo que sí es posible constatar es el crecimiento de la marginación y la pobreza. Se sigue luchando porque las libertades fundamentales del hombre, proclamadas en la Carta de los Derechos Humanos, se cumplan para

\footnotetext{
${ }^{6}$ Por ejemplo, se pueden consultar en Internet, entre muchas más, las siguientes direcciones: www.cinu.org.mx./temas/des_sost/ y www.unep.org/geo3/spanish/overview.

${ }^{7}$ Un libro muy interesante que narra la expoliación de los recursos naturales de Latinoamérica por parte de los países del norte, es el de Galeano (2003).
} 
la mayoría de los habitantes del planeta (onU, 2000), ${ }^{8}$ pues se observa una mayor profundización de las desigualdades entre los seres humanos. En la Declaración del Milenio sobre Desarrollo Humano 9 se señala que "en lugar de aprovechar el momento, los gobiernos del mundo avanzan a tropezones hacia un fracaso en desarrollo humano ampliamente anunciado" (ONU, 2005: 19).

En la posmodernidad ya no hay certeza de lo que se es y hacia dónde se va, tanto los individuos como la sociedad en su conjunto; se ha perdido la confianza absoluta en las instituciones, en los planes y programas de gobierno, en la ciencia y la tecnología como instrumentos para alcanzar el desarrollo de la humanidad, donde el futuro se predecía o se veía con claridad. Las diversas crisis que se presentaron durante el siglo xx (y que continúan en el XXI) dan cuenta de ese fracaso, el bloque socialista se derrumba, el capitalismo tradicional se tambalea, el Estado benefactor o de bienestar, interventor y paternalista falla (Mombrú, 2005). Los sistemas productivos son inoperantes, el modelo fordista pierde consistencia ante las nuevas condiciones del mercado, los grandes complejos industriales son desechables, lo importante es el éxito en la introducción de los productos en el mercado, con la automatización, el trabajador pierde el empleo y se incorpora, generalmente, al área de servicios (muchas veces irregular), ya no hay seguridad laboral, las organizaciones sindicales van perdiendo fuerza, se da paso al capitalismo salvaje neoliberal, donde al capitalismo industrial lo sustituye el capitalismo financiero; no se trata del imperialismo de una nación, sino del capital. De Sebastián (1997) lo define como una forma de conducir la economía cuyo objetivo es el lucro del sector privado en todos los campos económicos y sociales. Destaca una menor actuación del Estado, lo que favorece a la iniciativa privada (principalmente las grandes empresas globales) y sus intereses particulares, que el autor denomina inconfesables. Aunque el neoliberalismo no es un cuerpo de doctrinas homogéneo, se distingue por ese afán de privilegiar las actuaciones económicas de los agentes individuales pasando sobre los demás sectores de la sociedad. El libre mercado los beneficia y les permite obtener una mayor riqueza a través del intercambio de información y la

\footnotetext{
${ }^{8}$ Conviene recordar que desde la Revolución francesa, en 1779, ya se proclamaban la libertad, la igualdad y la fraternidad como derechos del hombre.

${ }^{9}$ El índice de desarrollo humano (IDH) es un indicador compuesto por tres dimensiones de bienestar: ingresos, educación y salud (ONU, 2005).
} 
racionalidad de los agentes privados se sustenta en la eficiencia de los recursos económicos escasos. Propugna por la no intervención del gobierno en la economía, el menor gasto público en seguridad social y, en general, en actividades no productivas, pues limitan a la iniciativa privada.

La posmodernidad se despliega en un mundo globalizado gracias al avance de las tecnologías de la información, donde se han generado profundas transformaciones que son históricamente estructurales, permitiendo la articulación de procesos sociales a distancia (Borja y Castells, 2000). La riqueza de personas, empresas o países depende de la interrelación de los movimientos de capital, de cadenas productivas y de distribución, así como de unidades de gestión. Se presenta la descentralización de las grandes compañías en pequeñas y medianas empresas, lo que constituye la empresa-red como una nueva forma de organización que hace la producción flexible. Las relaciones de trabajo y la estructura del empleo también se transforman. No obstante, es un proceso asimétrico, pues la globalización es a la vez incluyente y excluyente, únicamente incorpora lo que representa ganancias en cualquier parte del mundo, pero deja fuera lo que no tiene valor, como las personas no capacitadas. El consumismo se apodera de la sociedad aunque, paradójicamente, la mayor parte de la población no tiene acceso a la mayoría de esos productos, ya sean básicos o suntuarios. Para algunos, la globalización es una consecuencia de la modernidad pues las bases de ésta se refieren a la homogeneización de instituciones, experiencias y, por tanto, de condiciones o nivel de vida para los seres humanos, pero en la realidad sólo algunos sectores se benefician. Al parecer, la sociedad de la información global determina lo local y la economía se estructura a través de flujos electrónicos que relacionan regiones distantes entre sí. Si bien el proceso de globalización se inicia en el ámbito de las comunicaciones, con el tiempo trasciende este campo y se presenta una interdependencia de las actividades económicas y culturales. Los medios parecen estandarizar la cultura y la identidad se desvanece; desde el punto de vista cultural, pareciera que el imaginario del individuo también se globaliza por medio de los sistemas multimedia, que van absorbiendo a las culturas tradicionales, aunque algunas se resisten a la uniformidad, tienen que relacionarse; el reto es rescatar y conservar su identidad cultural.

Así, la cultura también es un medio para negociar el poder y contribuye a revalorar las diferencias culturales que faciliten el 
acceso al poder, de ahí que se considere el multiculturalismo como la base para lograr una armonía política que coadyuve a la construcción de la igualdad y la justicia social. La sociedad se organiza y actúa de acuerdo con su cultura, los individuos son portadores y creadores de cultura, pero ésta los rebasa, es la suma total integrada de rasgos de conducta aprendida dentro de una sociedad que se manifiesta y es compartida por sus miembros, o al menos por la mayoría de ellos; entre estas manifestaciones se encuentra la manera de utilizar sus recursos naturales y culturales, así como su cosmovisión de la naturaleza y del ser humano dentro de esa totalidad; dentro de la cultura pueden describirse todos los fenómenos sociales, modos de conducta, instituciones, organizaciones o procesos sociales (Geertz, 1995). En resumen, una cultura es el conjunto de las facultades y habilidades -no puramente instintivas- de que dispone un grupo de seres humanos para mantenerse vivo, singular y de forma colectiva. Con lo aquí expuesto se pretende hacer énfasis en que resulta indispensable crear una cultura de sostenibilidad ambiental (tanto desde la racionalidad como desde lo instintivo e intuitivo) que permita, entre otras acciones, incorporar proyectos de desarrollo local y de turismo sostenible.

Ante esta realidad llena de contrastes y confusión, se motiva una crisis en las ideas, en los valores y en las expectativas de personas y grupos. Si bien no se puede retroceder al pasado (que por cierto también permitió la marginación y la pobreza), hay ideas y valores que son importantes de rescatar, adaptar y mejorar, así como generar otros en beneficio de las mayorías, pues es un hecho que los modelos de modernización no funcionaron para todos. En este contexto social y político surge el concepto de posmodernidad en contraposición con la modernidad, que enfatizaba una nueva forma de organización del mundo; aunque aún no puede considerarse como una etapa de la historia de la humanidad, ya que apenas estamos en el inicio de la discusión y confrontación de ideas. Surge asimismo una nueva filosofía posmoderna que impacta y transforma las teorías sociales y políticas del momento. El discurso posmoderno tiene grandes variantes, desde cuestionamientos de los presupuestos de la izquierda, hasta los de la derecha, que se distinguen por ser críticos de las ideologías tradicionales. Pero cabría preguntarse si los cambios producidos en los últimos tiempos son una modificación de lo mismo o un salto estructural, cualitativo, hacia algo nuevo, es decir, si las contradicciones que caracterizan al mundo moderno están resueltas, superadas, o simplemente desaparecieron de esce- 
na. Otra postura declara que la modernidad no ha concluido y lo que se requiere es un replanteamiento basado en la construcción de una historia para el futuro. Héctor Leis (2001) critica la modernidad dominada por la razón y la califica como un proyecto insostenible, por lo que se requieren nuevas bases conceptuales que reconozcan una multiplicidad de interpretaciones e individualidades, estas posturas se basan en cierto relativismo del posmodernismo. Esta búsqueda de nuevas formas de interpretar y estudiar la realidad ha generado enfrentamientos entre importantes investigadores, como señala Antonio Arellano (2000), existe una guerra entre las ciencias exactas y las humanidades. ${ }^{10}$ Hoy en día no se puede negar el dominio de la tecnociencia, es decir, de la subordinación masiva de los enunciados cognoscitivos al criterio técnico. Pero lo mecánico y lo industrial son portadores de algo completamente distinto, aunque sean efectos de poder (Lyotard, 1999); por lo que se parte del supuesto de que una transformación o reforma ambiental que trascienda los ámbitos administrativos, técnicos e instrumentales implicaría una propuesta teórico-metodológica que epistemológicamente la sustente y un proceso de investigación que la legitime. A continuación se presentan algunos elementos que pueden constituir el fundamento sobre el cual se siga construyendo un paradigma alternativo.

\section{Propuesta para el análisis y planeación del desarrollo, la sostenibilidad y el turismo}

[...] es hora de nuevas alianzas, alianzas establecidas desde siempre, por tanto tiempo ignoradas entre la historia de los hombres, de su sociedad, de sus saberes y la aventura exploradora de la naturaleza, ya es tiempo de rendirse a las evidencias de que a cualquier nivel, la naturaleza ya no se aviene a ese paradigma clásico.

Ilya Prigogine (El nacimiento del tiempo, 1998: 13)

Ya sea que la humanidad transite hacia una nueva etapa histórica o simplemente se trate de otra fase de la etapa anterior, lo cierto es que éste es el momento propicio para proponer ideas alternativas para crear un presente aceptable para todos, a partir del

\footnotetext{
${ }^{10}$ En los últimos años se presentaron ataques contra los constructivistas, las feministas y los ambientalistas, los cuales se ubicaron dentro del posmodernismo. Asimismo, sociólogos como Bruno Latour, Michel Callon y John Law criticaron el relativismo epistémico, el irracionalismo y el intelectualismo, con lo que se identifican contrarios al posmodernismo en la ciencia (Arellano, 2000).
} 
cual se generen cambios positivos que construyan un futuro de bienestar para la humanidad. Si bien una característica del pensamiento moderno -basado a su vez en el pensamiento positivofue alcanzar el progreso a través de la aplicación de la ciencia y la tecnología, ya se comprobó (con los datos mencionados en el apartado anterior) que ése no es el mejor o único camino, pues deja a las grandes mayorías al margen de los beneficios que ha producido ese modelo de pensamiento y de acción. La racionalidad instrumental del pensamiento occidental no es suficiente, es necesario buscar una racionalidad ambiental que conjugue los avances de la ciencia y la tecnología en la solución de los problemas de la sociedad contemporánea -en particular los ambientales- con los valores de una nueva ética y de otros paradigmas que permitan reducir la brecha entre países, regiones y comunidades desarrolladas y las que se encuentran en vías de desarrollo o subdesarrolladas.

En este sentido, la perspectiva positivista tiene limitaciones cuando pretende experimentar, comprobar, evaluar y establecer leyes generales de la naturaleza y la sociedad en un mundo donde no se cumplen los supuestos en los que se fundamenta: sistemas en equilibrio estático regidos por leyes universales inmutables. Así, la metodología que propone esta perspectiva es rígida, aspira a medir y cuantificar todo mediante el uso de técnicas y métodos estadísticos y modelos matemáticos que pretenden describir con exactitud y precisión el fenómeno estudiado, para predecir con esa misma exactitud su comportamiento futuro. Este método se ha utilizado con cierto éxito en el área de las ciencias exactas y naturales, donde se pueden controlar las variables que intervienen en un fenómeno o proceso, pero cuando se llevan a la realidad no se tiene ese control y existen múltiples factores que van a influir y transformar lo que en el laboratorio parecía tan manejable y controlable. Esto se vuelve más complejo en lo que se refiere a la sociedad y más aún cuando se estudia la relación naturaleza-sociedad o ambiente. En relación con el turismo, la mayoría de sus estudios se realizan desde el campo administrativo, siendo los más comunes sobre cuantificación de las entradas y salidas de turistas, el monto de las ganancias generadas por las divisas, el número de empleos generados, entre otros indicadores; muchos otros son de carácter mercadológico donde también predomina la medición y la evaluación. Aunque en los últimos años se incorporó la variable ambiental, y en particu- 
lar el enfoque de la sostenibilidad, en las propuestas todavía se utiliza más la perspectiva positivista.

Por ello la problemática ambiental, el desarrollo, la sostenibilidad y el turismo no se pueden analizar exclusivamente desde la perspectiva clásica positivista, pues estos aspectos se deben considerar como procesos socionaturales que se alejan del equilibrio y están sujetos a alteraciones y fluctuaciones que impiden predecir con certidumbre su evolución futura; es decir, estamos hablando de un sistema complejo. En consecuencia, suponer que con el uso de nuevas tecnologías y ecotecnias se van a resolver estos problemas es una falacia. En realidad, esto tiene un origen cultural, no tecnológico, de ahí la necesidad de analizar la problemática ambiental como una dificultad de la civilización y trabajar, conjuntamente, los científicos de las áreas sociales y humanísticas con los de las ciencias exactas y naturales, traspasando los límites de cada disciplina y del enfoque interdisciplinario que ha mantenido esas divisiones. Así, se deben buscar otros paradigmas que ofrezcan más posibilidades para explicar los fenómenos ambientales (socionaturales) que se dan en un espacio geográfico y proponer soluciones; ya que se trata de encontrar vías alternativas que permitan llegar a la raíz de los problemas. De esta manera, el espacio geográfico se entiende como el espacio relativo, el que constituyen los factores naturales (físicos y biológicos) más la acción del ser humano; no como algo estático, sino como el lugar donde se entrelazan la naturaleza y la sociedad en un proceso dinámico, producto de su pasado histórico, pero siempre en evolución.

Otra dificultad del paradigma dominante que se refleja en el diseño de los sistemas de análisis, evaluación y planeación del desarrollo es que se construyen de acuerdo con la necesidad de ofrecer soluciones a los problemas económicos y sociales que presentan los países donde se elaboran, generalmente desarrollados. La ciencia y la tecnología no son neutrales ni universales, es indispensable considerar las particularidades y condicionantes de cada caso. En este contexto, el proceso de planeación del desarrollo no siempre incorpora la dimensión ambiental, como tampoco las características de los países periféricos en los que se pretende poner en práctica. Para el caso específico de México, y en general de Latinoamérica, los instrumentos utilizados se diseñaron en países desarrollados donde las estructuras económicas, políticas, institucionales, sociales y culturales, el proceso histórico, la disponibilidad de recursos (naturales, económicos, financie- 
ros y humanos) y los problemas que han enfrentado son diferentes a los que se presentan en países menos desarrollados. Por tanto, la ciencia positivista y la planeación tradicional que pretenden elaborar conocimientos y diagnósticos exactos para establecer leyes universales y pronósticos precisos, en situaciones predecibles y estáticas, han perdido credibilidad. Últimamente se ha considerado el problema como un asunto de precisión tecnológica, sin tomar en cuenta que el estado actual del ambiente es resultado del proceso evolutivo de los ecosistemas (cantidad y calidad de los recursos, disponibilidad y aspectos que rigen su preservación y existencia) y -de manera más determinante y acelerada- de los factores culturales -básicamente la forma e intensidad con que la sociedad se apropia y utiliza los recursos naturales-, así como los valores que sustentan su racionalidad, donde las cuestiones técnicas son parte de los aspectos que se deben analizar, pero no los únicos. La cantidad y disponibilidad de los recursos naturales depende de los procesos del medio biofísico, por lo que es necesario identificar, cualificar y conocer dichos procesos; en tanto que su utilización depende de los valores, prioridades y formas en que la sociedad aprovecha esos recursos, de su cultura. El subsistema sociocultural se determina y manifiesta en los aspectos socioeconómicos, en el estilo de desarrollo y en el nivel de desarrollo. Durante el proceso de planeación deben incidir estos puntos, adecuando los medios para afianzar en el proceso de desarrollo las posibilidades y restricciones impuestas por el medio biofísico. En la práctica, se trata de un proceso de ajustes y transformaciones del subsistema sociocultural y sus estilos de desarrollo que conduzcan a preservar, defender y mejorar el ambiente, así como una estrategia para ejecutar estas acciones.

Otra limitación de este paradigma se deriva, sencillamente, de cómo se maneja el concepto de ambiente, pues aunque se entiende como la conjunción naturaleza-sociedad, como se constata en la definición que propone Pablo Bifani:

La relación hombre (sociedad)-medio ambiente natural es, antes que nada, una relación unitaria que implica una interacción recíproca entre ambas entidades, que aisladas de su dialéctica carecen de sentido [...] No existe, por lo tanto, una escisión entre sociedad y naturaleza o, mejor dicho, entre sistema social y sistema natural, debiendo éstos ser concebidos como partes de un todo, como dos subsistemas interrelacionados, integrados a un sistema mayor (1999: 30). 
En la práctica únicamente se considera al subsistema natural; esto es, su deterioro y destrucción: la contaminación del agua, del aire y del suelo, la desaparición de especies, el efecto invernadero o la destrucción de la capa de ozono, pero dejan fuera los problemas que afectan a la sociedad, como las enfermedades debidas a la contaminación, el estrés, la contaminación visual y auditiva, la pobreza y la marginación. En tanto se continúe aplicando el concepto de ambiente como sinónimo de naturaleza separada de la sociedad, no será posible explicar ni proponer soluciones a su problemática. Es un error lógico, la totalidad, el ambiente, no puede ser una parte la naturaleza. El ambiente es el todo, el sistema complejo producto de la interrelación entre ambos subsistemas. Por ello, cuando se habla de ambiente se debe tener presente que se hace referencia a ambos subsistemas y que no se entienden separados, al menos cuando se analiza la problemática ambiental desde la perspectiva de la sostenibilidad.

Ante estas circunstancias, se propone una perspectiva ambiental sustentada en el enfoque holístico, el cual se refiere a considerar al ambiente como un sistema complejo, la totalidad constituida por la naturaleza y la sociedad, es decir, que incluya hechos y fenómenos naturales y socioculturales, con dinámicas propias, pero indisolublemente ligadas en mayor o menor intensidad; aunque por supuesto la naturaleza puede existir sin la sociedad, el ser humano depende de un sustrato natural para su subsistencia. Esta visión difiere, por ejemplo, del enfoque holístico manejado desde la teoría general de sistemas y otras propuestas positivistas, cuya visión es el resultado de estudiar un fenómeno y los elementos o compuestos que lo constituyen o tienen alguna relación con él, pero dentro de uno de los subsistemas, como ha sido el caso de la actividad turística (desde Leiper, 1979; hasta Osorio, 2004); pero, cuando mucho, podría considerarse como un subsistema parcial pues se analiza fuera del sistema complejo que es el ambiente, se aísla de su contexto y, además, se pretende mantener su funcionamiento inmutable y racional (desde la lógica económica); es decir, mantener el equilibrio del sistema a través del conocimiento de las leyes que rigen su comportamiento. Lo holístico no se refiere a estudiar un fenómeno y todo lo que tiene que ver con él, sino analizar ese fenómeno como parte del sistema complejo naturaleza-sociedad o ambiente. No se trata de regresar al reduccionismo tradicional, pero tampoco es posible pensar que se podrán incorporar todos los elementos, componentes, relaciones y efectos que constituyen el hecho o fenó- 
meno a estudiar, es necesario establecer límites al sistema complejo, desde la escala hasta los elementos que se consideren básicos para su análisis, incluyendo tanto aspectos naturales como socioculturales. Lo complejo no tiene por qué ser complicado.

En este contexto, se rechaza el interés predictivo y de control para mantener el equilibrio del sistema que propugna, entre otras cosas, la ciencia tradicional (positiva); más bien se busca comprender el comportamiento del sistema para tratar de dirigirlo hacia los objetivos comunes establecidos por las propias comunidades, en el entendido de que no se puede manipular el ambiente (como en el laboratorio experimental, en donde hasta las muestras son manipuladas), pues existen múltiples interferencias, fluctuaciones o perturbaciones que hacen imposible un estado absoluto de equilibrio o estabilidad permanente. El sistema complejo siempre estará en evolución, en función de su flexibilidad y capacidad de autoorganización, así como de los mecanismos de retroacción ante las modificaciones de las condiciones de contorno o internas, pues son sistemas abiertos donde los procesos son irreversibles.

En este sentido, tratar de evaluar y establecer una metodología única para comprobar que un sistema es sostenible -como pretendería la ciencia tradicional- resultaría una falacia, ya que verificar empíricamente el término sostenibilidad requeriría comprobar los postulados en que se fundamenta, evaluar con certeza y exactitud-generalmente a través de modelos matemáticos y/o con sistemas sofisticados de diversa índole-fenómenos que siempre están expuestos a perturbaciones, que no se pueden aislar de su contexto y que, dependiendo del sistema complejo del que se trate (macro, micro), presentará condiciones distintas, tanto naturales como culturales, por lo que tampoco es posible establecer leyes generales y pronósticos precisos al estilo positivista. Como señala Edgar Morin (2004), ahora es más importante explicar la complejidad que establecer leyes del comportamiento de sistemas estables y reversibles en el tiempo, que sólo representan un segmento particular y limitado de la realidad; además, se deben evitar las disociaciones entre disciplinas que fragmentan lo humano y, yo diría, que fragmentan la realidad, el ambiente. No se trata de yuxtaponer los conocimientos dispersos sino de articularlos y considerar las contradicciones, tanto al interior del subsistema sociocultural, como del natural. La complejidad, de acuerdo con Morin (2001), se constituye de elementos heterogéneos inseparablemente asociados y presenta la paradoja del 
uno y lo múltiple. La complejidad es el tejido de eventos, acciones, interacciones, retroalimentaciones, determinaciones y azares que constituyen nuestro mundo fenoménico. La complejidad se representa, entonces, con los rasgos inquietantes de lo enredado, de lo inextricable, del desorden, la ambigüedad y la incertidumbre. Estos rasgos son, precisamente, los que exigen del conocimiento la búsqueda que nos lleve a cierto grado de orden en los fenómenos, minimizar lo incierto, disminuir la ambigüedad, es decir, seleccionar los elementos del orden y de cierto grado de certidumbre, clarificar, distinguir, jerarquizar. Con estas aseveraciones se complementan las ideas de García (1986) sobre los sistemas complejos, en tanto ecosistemas naturales que han sufrido la acción del ser humano -ya sea por la explotación de los recursos naturales o por el establecimiento de asentamientos humanos-, así como de que el concepto sistema es una construcción intelectual que tiene ciertos objetivos y que está constituido por elementos elegidos en función de su interacción dinámica, con la finalidad de representar y describir un fenómeno o una realidad compleja (Ellul, 2002). Al definir un sistema complejo se pretende estudiar un "trozo de la realidad que incluye aspectos físicos, biológicos, sociales, económicos y políticos” (García, 1986: 50). Existen múltiples formas de abordarlo, dependiendo de los objetivos del investigador, por lo que no se le puede dar una definición única. Es importante señalar que en esta propuesta el concepto sistema complejo se maneja en dos ámbitos: el primero se refiere a una reflexión conceptual que se aplica al término ambiente y, el segundo, a su expresión territorial, la región.

Ante estas consideraciones, y de acuerdo con Prigogine, "No podemos tener la esperanza de predecir el futuro, pero podemos influir en él. En la medida en que las predicciones deterministas no son posibles, es probable que las visiones del futuro, y hasta las utopías, desempeñen un papel importante en esta construcción" (1998c: 412). La propuesta metodológica que se presenta pretende, por un lado, aplicar los conceptos y aspectos teóricos de los sistemas complejos y la sostenibilidad y, por el otro, establecer un modelo básico de planeación del desarrollo local sostenible a partir de un proyecto turístico, que permita establecer los cimientos de lo que sería una metodología desde la perspectiva de la complejidad. Para ello se trabajaron las siguientes premisas o principios: 
- Principio de sostenibilidad: que las actividades llevadas a cabo en un espacio geográfico propicien condiciones que mejoren la calidad del ambiente (natural y sociocultural) en un proceso permanente e irreversible de evolución.

- Principio de complementariedad: fomentar la diversificación de actividades que favorezcan la autosuficiencia a partir de la autodeterminación de las comunidades insertas en un espacio geográfico. Desde el punto de vista epistemológico, se busca propiciar la complementariedad de teorías y metodologías.

- Principio de sistemas complejos: la sociedad constituye el subsistema sociocultural inseparable, interrelacionado e interdependiente del subsistema natural, juntos constituyen un hommoecosistema, una totalidad indisolublemente integrada.

Estas premisas se retomaron principalmente de teóricos como Enrique Leff (1990, 1994, 2000 y 2002) y David Barkin (1998, 2000 y 2001) para el principio de sostenibilidad; de Edgar Morin (2001 y 2004) para el principio de complementariedad y complejidad y de Rolando García (1986, 1988 y 1994) para el principio de sistemas complejos. De estas premisas se derivan:

- Desarrollo sostenible: como ideología o precomprensión culturalmente asumida de ambiente.

- Desarrollo local: el mundo inmediato, cierto espacio geográfico (en este caso, rural).

- Turismo armónico: cooperación y participación de actores sociales (funcionarios, investigadores y población rural) para el desarrollo del turismo sostenible (armonía entre la sociedad y la naturaleza), lo cual se apoya en la teoría de la acción comunicativa de Habermas (2001).

Como resultado de lo anterior, se proponen las siguientes categorías de análisis:

- Hommoecosistema

- Aprovechamiento ambientalmente intuitivo-racional

- Turismo armónico

- Planeación integrativa participante 
Estos principios y categorías de análisis se han trabajado en diversas investigaciones y se deben seguir afinando y reconstruyendo, de acuerdo con los avances y resultados que se obtengan. En este artículo se presentan, a modo de síntesis, las representaciones simbólicas, conceptuales y contextuales que se complementan con las figuras I, II, III y IV y la tabla 1, las cuales se comentan posteriormente. La explicación gráfica de esta interacción entre las premisas o principios y las categorías de análisis propuestas, se observan en la figura I.

Figura I

Categorías de análisis

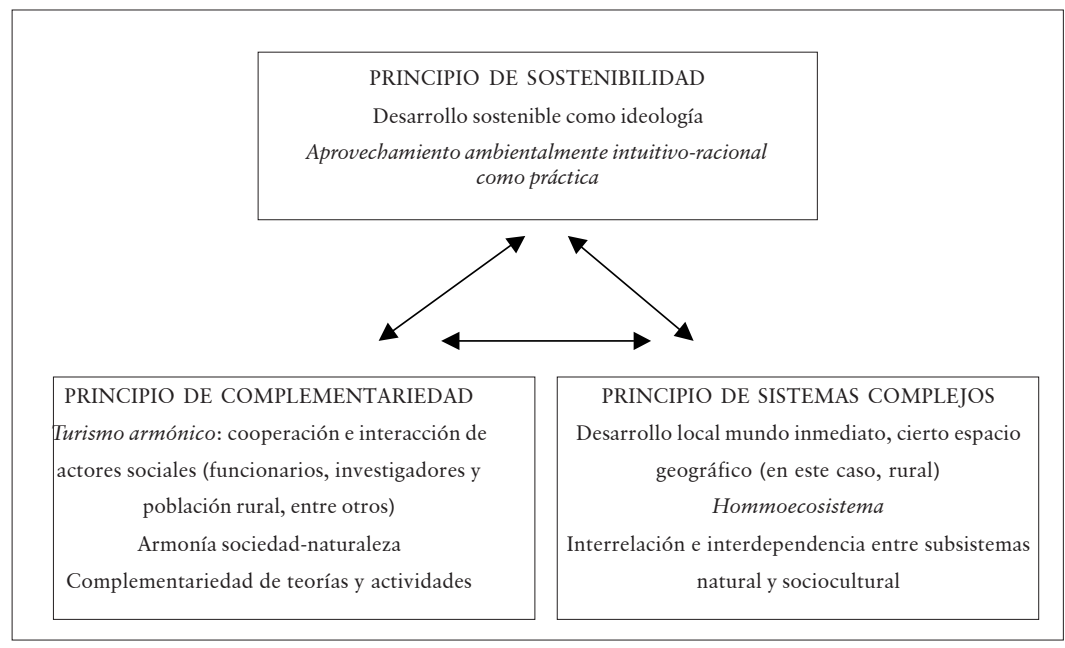

Fuente: Elaboración propia.

Para construir y explicar estos principios y categorías de análisis se retoma el postulado de la acción comunicativa de Habermas (2001) que se caracteriza por el nivel de complejidad de los actos del habla, que simultáneamente expresan una propuesta y la oferta de una relación interpersonal y una intención del que habla. Así, las acciones son manifestaciones simbólicas del actor cuando entra en relación con un mundo, en este caso se refleja en el desarrollo local; el entendimiento tiene lugar en el trasfondo de una precomprensión imbuida culturalmente -aquí me refiero al desarrollo sostenible como ideología-, pero cuando se realiza la interacción, es decir, cuando los participantes negocian, entran en procesos cooperativos de interpretación, cuyo resultado es el turismo armónico. Ninguno de los implicados tie- 
ne un monopolio interpretativo, en este caso, los actores (funcionarios, investigadores y población rural) son quienes buscan un consenso y lo someten a criterios de verdad, de rectitud y de veracidad, es decir, a criterios de ajuste y desajuste entre los tres mundos con que el actor contrae relaciones. "Estas relaciones son las que se dan entre la manifestación y el mundo objetivo, como conjunto de todas las entidades sobre las que son posibles enunciados verdaderos; el mundo social, como conjunto de todas las relaciones interpersonales legítimamente reguladas; y el mundo subjetivo, como totalidad de las vivencias del hablante, a las que éste tiene un acceso privilegiado" (Habermas, 2001: 144).

Por otro lado, la sostenibilidad es un concepto manejado ampliamente, pero que cada disciplina le otorga diversos atributos, principios y criterios de evaluación propios de su área del conocimiento, por lo que es indispensable definir cómo se maneja el concepto desarrollo sostenible. En este trabajo se concibe como una ideología que se manifiesta en un proceso permanente hacia estadios superiores de desarrollo humano, más que una meta que hay que alcanzar y mantener. Por ello se destaca que no existen límites absolutos al desarrollo, sino que éstos los impone el actual estado de la tecnología y de la organización económica y social, el efecto negativo de las actividades en los recursos naturales y en el medio ambiente en general y la capacidad de la biosfera para absorberlos. Así, para que se pueda alcanzar el desarrollo sostenible es necesario cubrir ciertos requisitos, entre ellos la eliminación de las disparidades entre el poder económico y político (que se resolvería a través de la participación comunitaria), la incorporación de cambios en la gestión de los recursos naturales (iniciando con las microrregiones) y la obtención de un potencial económico completo en todos los países (empezando en el ámbito local). Es decir, el desarrollo sostenible implica un proceso de cambio en el que se encuentren en armonía: la explotación y manejo de los recursos naturales y culturales, las inversiones, la tecnología y las transformaciones institucionales, todo ello con el fin de contribuir al aumento del potencial actual y futuro para satisfacer las necesidades materiales y las aspiraciones del ser humano. Los aspectos fundamentales del desarrollo sostenible son: la integración de lo económico con lo ecológico y un replanteamiento de los valores y de las necesidades humanas. No obstante, al momento de aplicar este concepto surgen dificultades y se derivan propuestas alternativas que llevan a generar una discusión muy importante en torno al desarrollo sosteni- 
ble, entre ellas destaca la conocida como Modelo Comunitario de Desarrollo Sostenible (MCDS) (Tetreault, 2004), que incorpora aspectos manejados por Leff, Barkin y Toledo. Es precisamente este modelo el que sirve de referencia para nuestra propuesta donde entre otros aspectos, además de los señalados, se deben considerar la autodeterminación, la autosuficiencia y la diversificación (Barkin, 1998). El MCDS se enfoca a las comunidades rurales y se fundamenta en la recuperación y fortalecimiento de las culturas tradicionales y las economías de autosubsistencia, para satisfacer primero las necesidades de la propia comunidad y después para el mercado externo. Por ello fomenta la autosuficiencia y la autonomía de la comunidad, para que sea capaz de resolver sus propios problemas y controlar su destino; revalorar su cultura para rescatar su identidad; fomenta el uso de tecnologías tradicionales y promueve la diversificación de actividades. En esta propuesta se incorporan algunos aspectos que se ubican dentro de lo que se denomina etnoecología; los estudios de Toledo $^{11}$ se enfocan hacia la solución de los problemas ecológicos generados por los sistemas productivos en las zonas rurales y propone rescatar conocimientos de carácter empírico de los grupos indígenas. ${ }^{12}$

Para corregir la limitación del concepto de ambiente en cuanto a la separación que se hace de los medios natural y sociocultural, se propone el concepto hommoecosistema (figura II), que es un recorte del ambiente entendido como sistema complejo, con un componente natural y otro sociocultural indisolublemente ligados que interactúan en un proceso dinámico e interdependiente, y que la naturaleza no es únicamente la que abastece de materias primas y receptáculo de los desechos generados por la sociedad, sino más bien el soporte de la vida misma. Por ello se deben considerar las características y la evolución de los ecosistemas y de sus componentes, entre ellos los recursos naturales, pero también la acción transformadora de la sociedad. Por otro lado, el hommoecosistema se puede estudiar en diferentes escalas espaciales, desde el planeta en su conjunto, hasta pequeñas áreas a las que se denomina regiones (macro, meso y microrregiones).

${ }^{11}$ La obra de Víctor M. Toledo es muy extensa, destacan, entre otros, los estudios realizados en el estado de Michoacán (Lago de Pátzcuaro).

${ }^{12}$ De este enfoque vale la pena destacar las estrategias de uso múltiple que se refieren a generar una gran variedad de productos en pequeñas cantidades que satisfagan las necesidades del campesino, a través de la máxima utilización de las unidades ecogeográficas o ambientales donde se mantiene la heterogeneidad espacial y la diversidad biológica (Toledo, 1989). 
Figura II

Ambiente como un hommoecosistema (Recorte espacio geográfico: macrorregión, región, microrregión)

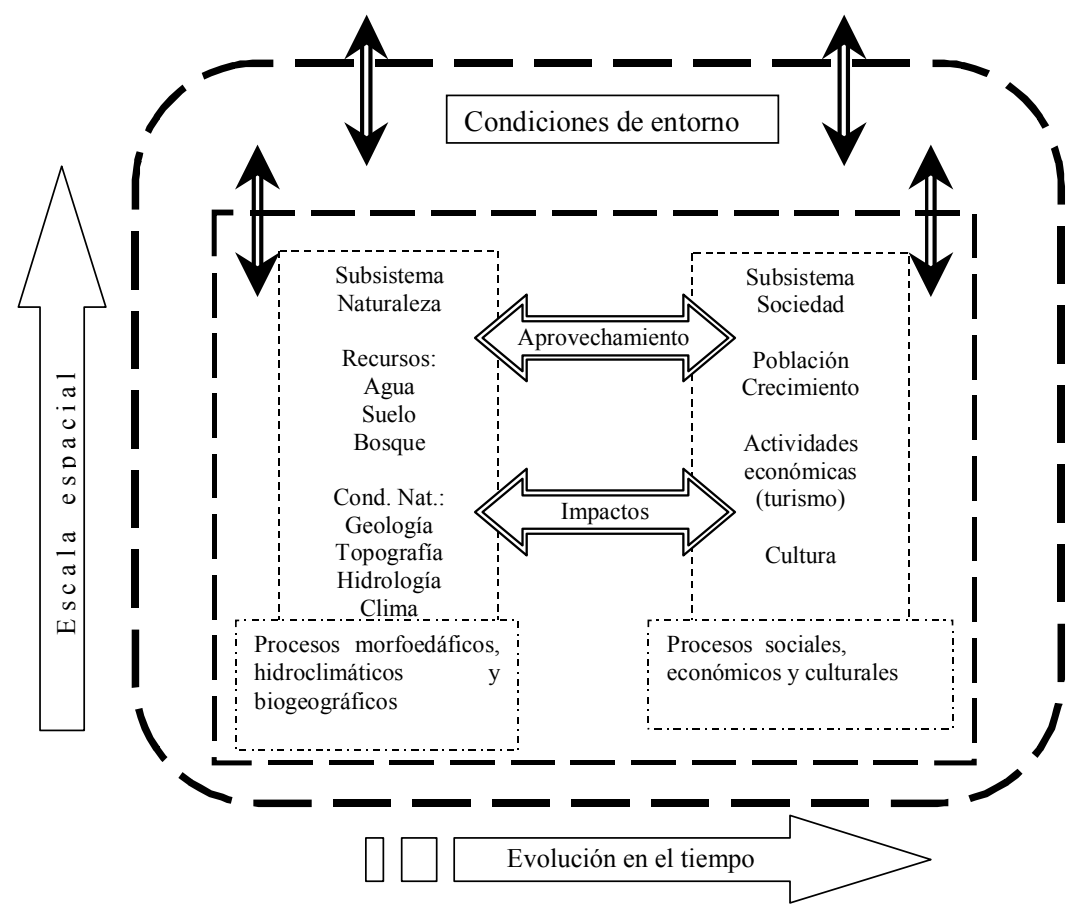

Fuente: Elaboración propia.

Se debe tener presente que el concepto hommoecosistema es un recurso teórico que permite un acercamiento a la realidad, pero que finalmente se refiere a un objeto concreto que se manifiesta en el territorio y que constituye una región geográfica o una microrregión (figura IV). Asimismo, el concepto región también es un recurso teórico que ha cobrado una renovada importancia en la posmodernidad, como lo indica Blanca Ramírez: "las regiones aparecen como testimonio palpable de nuestro paso efímero a través de los territorios que hombres y mujeres usamos, apropiamos, transformamos, sentimos e imaginamos como parte del devenir histórico de nuestra existencia” (2003: 5). ${ }^{13} \mathrm{La}$

${ }^{13}$ En el análisis territorial se entrecruzan campos específicos del conocimiento geográfico, económico y sociológico, entre otros, que integran tres áreas multidisciplinarias o niveles de debate: a) filosófico-epistemológico (reflexión concepto espacio- 
región puede presentar varias escalas, de acuerdo con los criterios del investigador, siempre que mantengan cierta unidad y diferencia con su entorno, en este caso se habla de una macrorregión, la parte central del país; la región, Valle de Toluca, y la microrregión, San Miguel Almaya.

Dado que también hay confusión en la interpretación del concepto aprovechamiento racional de los recursos naturales, es pertinente comentar que, si bien el resultado de esta explotación desencadenó el deterioro del ambiente, en realidad este aprovechamiento responde de manera exitosa a la lógica del capital o a la lógica o racionalidad económica de obtener las mayores ganancias al menor costo y en el menor tiempo. Por lo anterior es indispensable incorporar el concepto aprovechamiento ambientalmente intuitivo-racional de los recursos naturales y culturales de una región; el cual se realizará en función de las características propias de dichos recursos, de los conocimientos científico y tradicional (intuitivo), tanto de los científicos como de los miembros de la comunidad, para permitir que se utilice en beneficio de la población, sin poner en riesgo su existencia y aun puedan mejorarse; es decir, que se usen y no permanezcan como un museo; que se restauren si están deteriorados; y que se protejan a través de actividades que soporten o promuevan, en el entendido que todo en la Tierra está en evolución. En este contexto, el turismo y las demás actividades deben formar parte integral del ordenamiento ambiental del territorio y de otros instrumentos de planeación.

La tercera categoría de análisis que se propone es el turismo armónico como la actividad central que impulsa el desarrollo local, pues su objetivo es rescatar y proteger los recursos naturales y culturales de una región, favoreciendo la permanencia de los ecosistemas y sus procesos biológicos básicos y generando beneficios sociales y económicos al fomentar mejores niveles de vida para el visitante y la comunidad, a partir del aprovechamiento ambientalmente intuitivo-racional de estos recursos, al tiempo que permite combinar actividades primarias, secundarias y las orientadas a los servicios y el comercio. Esta complementariedad constituye una ventaja a explotar porque permite vincular las distintas actividades de la población y dar respuesta a las ne-

tiempo, concepciones ontológicas de los problemas sociales), b) de planeación y transformación económica y social, y c) de planeación, políticas estatales, instituciones y el poder; aunque todas ellas dan prioridad a lo urbano sobre lo rural (Ramírez, 2003). 
cesidades de empleo para alcanzar mejores ingresos y, con ello, elevar la calidad de vida de la población, objetivo común con el desarrollo local en que la organización y ejecución de iniciativas derivan de la comunidad a partir del aprovechamiento de recursos propios. Las actividades turísticas o recreativas que se llevan a cabo en zonas rurales o áreas naturales y que tienen como elemento básico la oferta de la cultura rural se consideran dentro del turismo rural. Aunque el concepto de turismo armónico puede y debe aplicarse a todas las modalidades turísticas (Serrano y Morales, 2002).

Se considera que se transita hacia el desarrollo local cuando se presentan proyectos derivados de iniciativas de la comunidad, cuando su organización y adecuación en términos técnicos y prácticos le dan factibilidad a tales iniciativas y permiten a la población local mejorar sus condiciones de vida, y cuando incluyen premisas como la amplia y activa participación de la población en el rescate de los niveles productivos necesarios y la identificación de los recursos disponibles para que se utilicen de manera más eficaz. Esto se relaciona directamente con la posibilidad real de obtener los resultados deseados y que los actores implicados en este proceso logren entender su nuevo papel y responsabilidades sociales: tomar conciencia, participar y generar dicho desarrollo, cumpliendo cada uno con lo que le corresponde. El desarrollo local involucra a una sociedad local con una identidad cultural y capacidad de decisión sobre el manejo de bienes económicos en un territorio, a un gobierno local y actores con lógicas e intereses diversos puestos en un plano de relativa igualdad (aunque distintas responsabilidades) para producir procesos locales que generen riqueza, valores comunes y bienes localmente gestionados (César et al., 2003). Otros autores como Martínez (2003) definen al desarrollo local como un proyecto en el que se combinan crecimiento económico, equidad, mejora sociocultural, sostenibilidad ecológica, equidad de género, calidad y equilibrio espacial teniendo como base un proceso de concertación de los diversos agentes de un municipio, a saber: gobierno, sector privado y sociedad civil cuyo objetivo principal es elevar la calidad de vida de quienes viven, trabajan e interactúan en dicho territorio. Adicionalmente, Blakely (1994) menciona que el desarrollo local involucra un proceso orientado a formar nuevas instituciones, desarrollar industrias alternativas, transferir conocimiento, así como mejorar la capacidad para producir mejores o nuevos productos y negocios. Las comunidades deben ven- 
der sus recursos de manera inteligente y generar ventajas competitivas que les permitan mantener su base económica. Se caracteriza por el desarrollo endógeno, el potencial humano local, institucional y de recursos naturales.

Las actividades que proponemos se desarrollan en un espacio relativo o geográfico a escala local, que es el soporte material sobre el cual se asienta el ser humano y trabaja, pero que va más allá de la idea determinista de depender únicamente de él, aquí se conjuga con el concepto de hommoecosistema. Así, se toma el concepto de región como el espacio creado por el ser humano y que refleja su cultura, pero que se desarrolla sobre un espacio natural alterado por la acción humana. La organización del espacio regional también refleja los procesos sociales y el orden jerárquico del sistema económico y político de cada región, estableciendo relaciones entre los diversos elementos de su estructura, al tiempo que mantiene relaciones con el exterior y está sujeta a las influencias de las condiciones del entorno y, a su vez, también influye en ellas. De ahí la dificultad para predecir el futuro de los hommoecosistemas, pues muchos factores y fenómenos pueden intervenir en su funcionamiento, desde el subsistema social-cultural (como situaciones políticas, económicas, sociales, culturales y tecnológicas) hasta el subsistema natural (inundaciones, sequías, terremotos, entre muchas más), que pondrían a trabajar los mecanismos de resistencia, recuperación o adaptación del propio sistema. En estos mecanismos, que en apariencia podrían considerarse similares, cada hommoecosistema (macro o micro) tiene particularidades que harían prácticamente imposible predecir, con certidumbre, cómo reaccionaría cada uno a similares intervenciones externas o generadas desde su interior. Por esta razón, cada zona de estudio presenta características propias, donde las interrelaciones e interdependencias de sus elementos dan por resultado estructuras diversas.

Como resultado del estudio e interpretación de las categorías de análisis se propone como categoría de aplicación la planeación integrativa participante (figura III). En esta categoría se hace énfasis en la necesidad de integrar los diferentes sectores de la actividad económica al plan de desarrollo sostenible, así como a las diversas dependencias y ámbitos (federal, estatal, municipal y local) del sector gubernamental, para que a partir de un modelo de ordenamiento ambiental del territorio se propongan los programas sectoriales que se complementen, en lugar de contraponerse a los principios de sostenibilidad o a los otros sectores; 
Figura III

\section{Planeación integrativa participante}

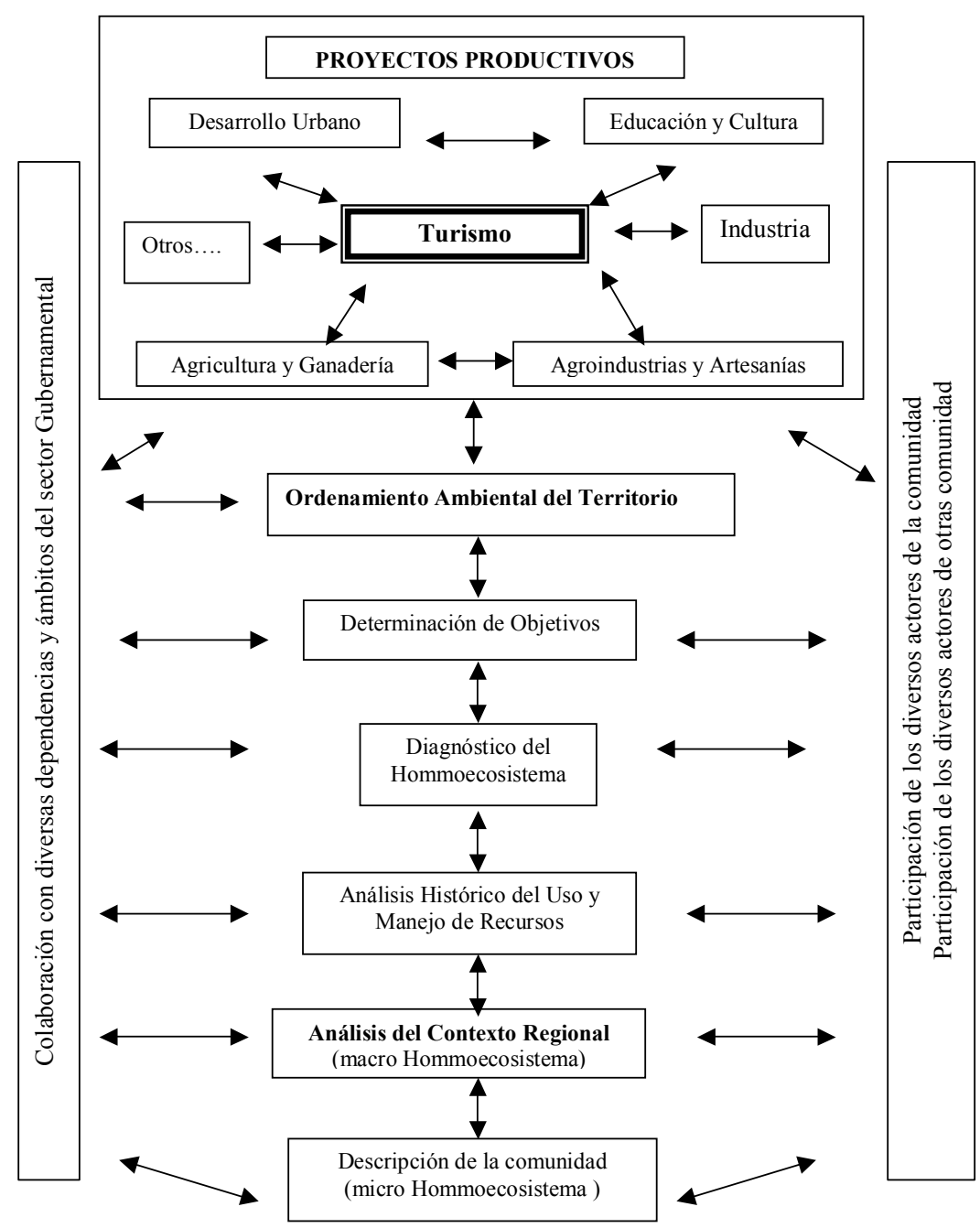

Fuente: elaboración propia.

asimismo, de manera paralela se fundamenta en la participación de los múltiples actores de la comunidad objeto de estudio y de las comunidades aledañas, todo ello considerado en el contexto regional.

Finalmente, con la intención de concretar las ideas expuestas y no dejar las propuestas en el nivel teórico, en la figura IV se representa a la comunidad de San Miguel Almaya como un hommoecosistema, esto es, un sistema complejo abierto, resultado de la inte- 
racción recíproca entre los subsistemas natural y sociocultural en una dinámica dialéctica inseparable, integrada e interrelacionada, en este caso una microrregión que forma parte de un sistema mayor, el Valle de Toluca (región) con sus componentes: los subsistemas natural y sociocultural. Se destacan los procesos fundamentales de cada uno de los subsistemas para explicar la problemática ambiental a partir de las relaciones entre ellos, derivados de la apropiación y aprovechamiento de los recursos naturales y los efectos que generan las actividades sobre los recursos y condiciones naturales, así como los impactos que éstos tienen en la sociedad, todo ello con la finalidad de analizar las posibilidades para desarrollar proyectos turísticos sostenibles.

Una vez establecidos los límites del hommoecosistema, en este caso una comunidad rural como parte de una región mayor, se distingue la estructura vertical o niveles de organización y la estructura horizontal o subsistemas. Para este estudio se eligieron los elementos fundamentales que explican la problemática ambiental y que, además, se vinculan con la actividad turística. La estructura vertical la integran los siguientes niveles:

- Ámbito internacional y nacional: contexto económico y políticas internacionales y nacionales, globalización, posmodernismo.

- Ámbito estatal y regional: políticas de desarrollo estatal, procesos de industrialización y urbanización, descentralización y desconcentración.

- Ámbito local: actividades económicas, organización social y agentes sociales.

En cuanto a la estructura horizontal, se identificaron los subsistemas:

- Naturaleza: condiciones y recursos naturales.

- Sociocultural: población, actividades económicas, aspectos políticos y sociales.

Las condiciones naturales de San Miguel Almaya están dadas por su ubicación geográfica en el Valle de Toluca, como parte de la cuenca alta del río Lerma. Para esta investigación, los elementos más significativos del subsistema naturaleza son el suelo, el agua (específicamente la laguna y los manantiales), así como la vegetación, correspondiente al bosque localizado en el volcán 
Figura IV

Hommoecosistema microrregión San Miguel Almaya

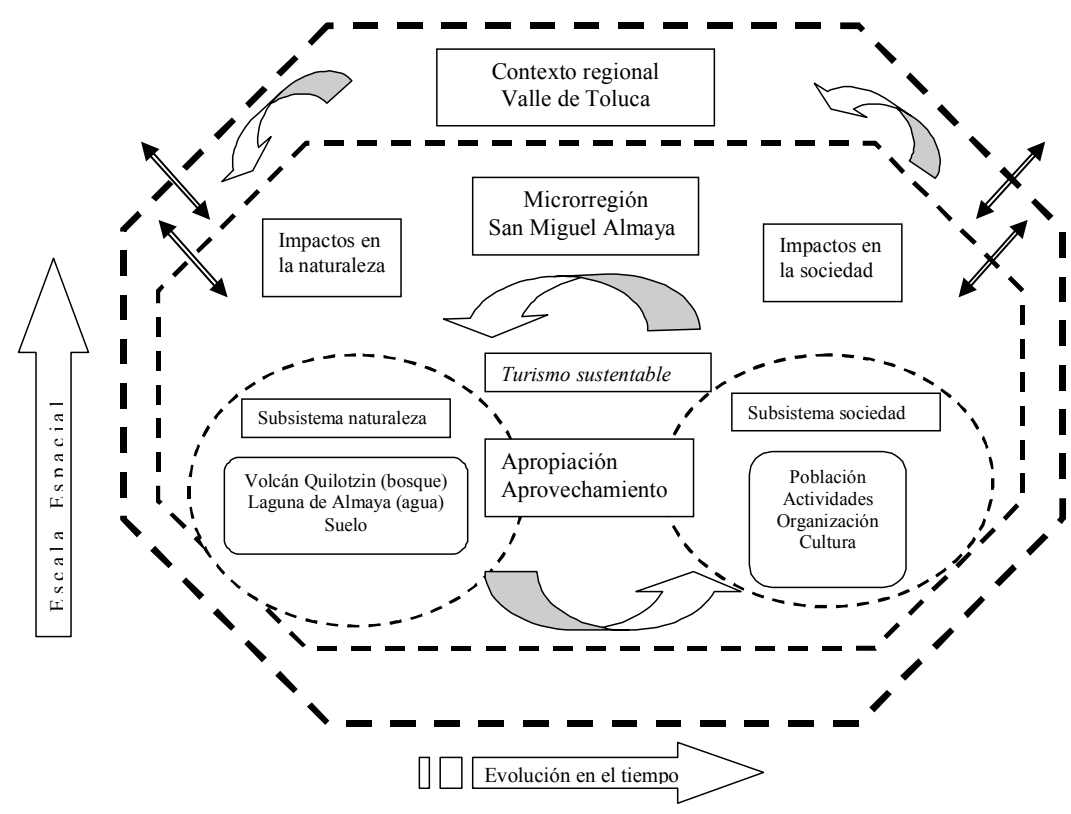

Fuente: Elaboración propia.

Quilotzin. Se considera al suelo como punto de partida para el análisis ambiental porque en él se reflejan de una u otra manera los demás elementos naturales y sociales, dado que sobre el suelo se desarrollan los seres vivos, entre ellos el ser humano quien se asienta y lleva a cabo sus actividades socioeconómicas en un espacio geográfico específico. La formación del recurso suelo es el resultado de procesos morfoedáficos, hidroclimáticos y biogeográficos que se llevan a cabo en una región determinada, por eso es importante conocer la estructura geológica, las formas de relieve y las demás condiciones naturales que determinan la existencia y características de los recursos naturales.

Se eligieron los tres elementos -suelo, agua y bosque- por su importancia ecológica, fundamentalmente por la recarga de agua al acuífero de la cuenca, la captura de $\mathrm{CO}_{2}$, su participación en el equilibrio climático (estabilidad en la temperatura, aporte de humedad), mantenimiento de la biodiversidad y la conservación de los recursos suelo, agua y vegetación. En relación con el primer recurso, el análisis se enfoca hacia los usos del suelo, la productividad y los problemas de erosión. En cuanto a la vegeta- 
ción, el bosque en el volcán Quilotzin, interesa la cobertura y la composición (principales especies). Respecto al agua, destaca su disponibilidad (para la demanda creciente) y su calidad referida a algunos aspectos de contaminación, así como su uso para actividades recreativas y desarrollo de especies piscícolas.

Dentro del subsistema sociocultural se destacan los procesos sociodemográficos, folklóricos, económicos y políticos que constituyen otro nivel de análisis, como podrían ser los subsubsistemas. En el primero se analizan los principales aspectos demográficos: población total, tasas de crecimiento, niveles de bienestar (grado de estudios, servicios públicos, ingresos); del folklórico destacan las principales costumbres y tradiciones (las fiestas religiosas, la gastronomía y los vestigios arqueológicos); del subsubsistema económico importan aspectos productivos en tanto el turismo genere ingresos y empleos (población económicamente activa, actividades desarrolladas, ingresos, diversificación de actividades); y en el político se enfocan las formas de organización y las relaciones entre los actores sociales y los organismos gubernamentales. ${ }^{14}$

La importancia sociocultural de los elementos elegidos está en función de su relación con los siguientes aspectos: a) elevar la calidad de vida (aumentar ingresos, capacitación, acceso a servicios recreativos, mejoramiento de servicios e imagen urbana, participación en la toma de decisiones), b) generar empleos dentro del sector turístico y en actividades vinculadas a éste, ya sea directa o indirectamente, como servicios de alojamiento, alimentos y bebidas, actividades recreativas y educativas, transporte, producción de alimentos (agricultura, ganadería y agroindustria) y otros artículos de consumo, comercio; c) elevar los ingresos teniendo en cuenta que el turismo se plantea como actividad complementaria; d) eficientar el aprovechamiento de los recursos disponibles; y $e$ ) revalorar y fortalecer los valores culturales. Un aspecto fundamental dentro de la investigación es considerar el componente cultural referido a los modelos de comportamiento de una sociedad, "modos como los seres humanos realizan las actividades implicadas en la vida diaria" (Beals, 1981: 260), desde los hábitos alimenticios, vestido, comportamiento con sus semejantes derivado del proceso de aprendizaje que le permitan desenvolverse adecuadamente en la sociedad a la que pertenece

${ }^{14}$ Para el análisis del subsistema sociocultural se están estudiando las propuestas de Capra (2002) y Luhmann (1998), entre otros. 
y en la cual es educado. Se retoman algunos aspectos de la ecología cultural propuesta por Steward (1977) en el sentido de que el ser humano se adapta al ambiente a través de su cultura, y sobre todo de Geertz (1995) en cuanto a que es dentro de la cultura donde se explican todos los acontecimientos sociales, modos de conducta, instituciones o procesos sociales.

En la tabla 1 se identifican las dimensiones y evidencias utilizadas para definir el hommoecosistema San Miguel Almaya, en función de los principios y criterios de sostenibilidad, con lo cual se pretende concretar la propuesta teórica y conceptual y reflejarla en la propuesta metodológica.

Conviene hacer una aclaración en cuanto al uso de evidencias en lugar de indicadores: los datos se manejaron como una expresión de la realidad que permite validar los principios y criterios de sostenibilidad, son elementos relevantes, sin embargo (el dato permite medir, como parte de la evaluación), no toda situación es posible y deseable de medir o evaluar, por lo que es indispensable elegir qué, cómo y para qué. A manera de reflexión se menciona lo que afirmó Paulo Freire (2001): la necesidad de evaluar es un síntoma de impaciencia, el cual es enemigo real del cambio. Así, la medición o evaluación adquiere su verdadera dimensión mediante la concertación de los significados libremente expresados y valorados por la interacción de los sujetos que participan del desarrollo sostenible, rescatando la esencia del fenómeno a estudiar, que refleje un carácter y procedimientos cuanticualitativos, justificados en términos de criterios éticos y no sólo cognoscitivistas. Así, por ejemplo, en el caso del bosque el objetivo es mantener la superficie forestal, por lo que primero se tiene que conocer el tamaño de ésta, es decir, contar con un dato (número de hectáreas), aunque no interesan las hectáreas en sí mismas, sino lo que representan: la existencia de un bosque que se quiere proteger y aprovechar intuitiva y racionalmente, y si es posible, con el tiempo aumentar esta superficie a partir de actividades propuestas en el proyecto de desarrollo. Por ello se necesita medir o determinar en qué condiciones se encuentra el fenómeno o circunstancia de interés, para tener una evidencia (que como su nombre refiere, muestra, designa) que confirme que se está logrando el objetivo planteado en el proyecto, no se trata sólo de medir, sino de describir, conocer y explicar una reali- 
Economía, Sociedad y Territorio, vol. viII, núm. 26, 2008, 313-356

343

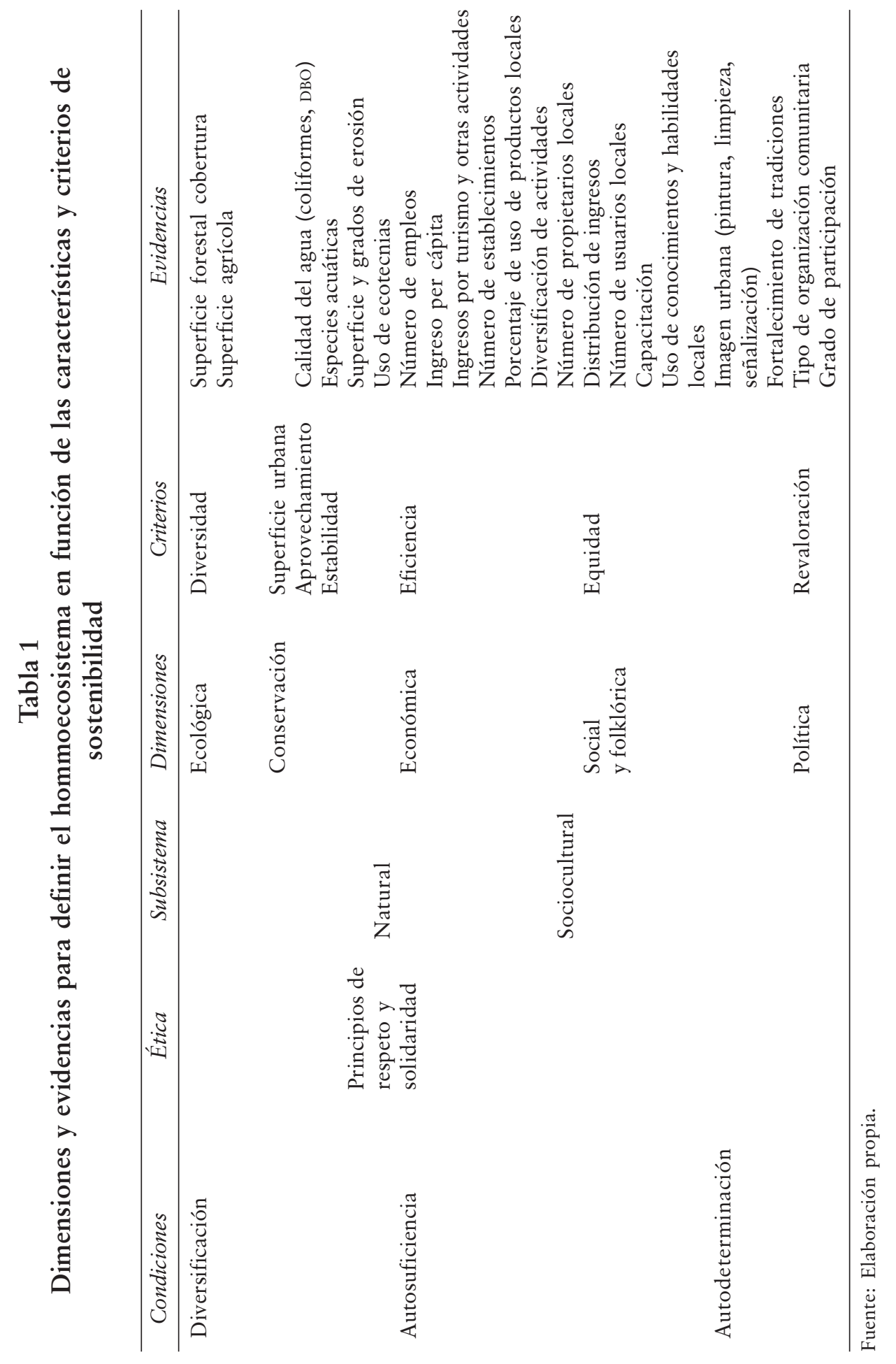


dad. ${ }^{15}$ De acuerdo con el detalle que se quiera alcanzar con la investigación, se requerirán más evidencias que den cuenta de las condiciones en que se encuentra el bosque (densidad, enfermedad, estructura, entre otras); pero en este trabajo se consideran las condiciones generales, tanto de este recurso como de los demás, por lo que se utilizan algunos datos que muestran las condiciones del ambiente.

Como se indicó, esta propuesta se aplicó en San Miguel Almaya, municipio de Capulhuac, a partir de la comunicación con diversos actores sociales: miembros de la comunidad y autoridades locales, estatales y federales en reuniones organizadas para tal efecto, a través de la aplicación de cuestionarios o de entrevistas, así como recorridos de campo, con el fin de orientar las necesidades e intereses de la comunidad y plasmarlos en el proyecto. Se trató de utilizar el modelo de educación propuesto por Freire (2001), en el que los participantes, guiados por diversas dinámicas, construyeron su concepto de proyecto reconociéndose como personas valiosas y capaces de llevarlo a cabo. Originalmente se contó con la participación de un grupo interdisciplinario de profesoras de las facultades de Turismo y de Planeación Urbana y Regional, ${ }^{16}$ que atendió a la población mediante diversos estudios en función de las necesidades detectadas, de aquí surgió el proyecto de turismo. En la primera etapa del trabajo comunitario conocimos a los miembros de la comunidad a través de sus diversos comités y tuvimos un acercamiento que permitió establecer un compromiso de colaboración para promover el proyecto de turismo rural gestionado por la propia comunidad. Para ello asistimos a diversas reuniones con los delegados y representantes del Comité de Bienes Comunales y los demás comités. Poco a poco se tuvo contacto con otros miembros de la comunidad y se elaboró un diagnóstico preliminar, con el apoyo de los demás participantes, para identificar la necesidad de proponer un proyecto de turismo armónico complementario con los demás temas tratados (desarrollo urbano, manejo de residuos, apoyo a la producción agrícola, entre otros). En la siguiente eta-

\footnotetext{
${ }^{15}$ Como señalan Aguado y Rogel, es necesario "recurrir a una constante vigilancia epistemológica en todo proceso de investigación, y hacer particular énfasis en lo apremiante de esta labor para el caso de los estudios de base empírica" (2005: 25); por tanto, es fundamental detenerse a reflexionar en la abstracción conceptual que está detrás de la medición y reconocer el papel del sujeto en la construcción del conocimiento.

${ }^{16}$ En esa primera etapa participaron la doctora Rosa María Sánchez Nájera y la maestra Elizabeth Díaz Cuenca, así como alumnos de las dos facultades cuyas investigaciones culminaron en ponencias y tesis de licenciatura y maestría.
} 
pa se decidió proponer un modelo de ordenamiento ambiental del territorio ${ }^{17}$ que incorpora los diversos usos del suelo, entre ellos el turístico, pero que pretende una visión integradora para el desarrollo local. Se llevaron a cabo varios recorridos de campo, tanto de manera individual como con miembros de la comunidad, y en algunos casos con autoridades (de los tres niveles de gobierno), para tomar en cuenta sus puntos de vista y mostrarles los inconvenientes o ventajas de ciertas propuestas. En la última etapa se elaboró, presentó y entregó el proyecto de turismo armónico a las autoridades. Posteriormente se constituyó una cooperativa que consiguió apoyo económico de la Secretaría de Turismo del estado; ante la difusión del proyecto se incorporaron miembros de las comunidades de Tlazala y Victoria y se propuso un corredor turístico entre las tres comunidades.

\section{Conclusiones}

Es conveniente destacar que considero que el pensamiento, sus diversas manifestaciones y la metodología para construirlo están permanentemente en evolución, y lo que hoy se acepta como un acierto, mañana se puede refutar. En este sentido, este artículo representa una primera aproximación a una propuesta alternativa para entender el mundo contemporáneo y la problemática ambiental; propuesta que se continuará trabajando pues siempre habrá elementos que podrán enriquecerla y a la vez aportar nuevos conceptos, categorías y técnicas que apoyen la construcción de o los paradigmas que permitan llegar a construir, también, una realidad en la que disminuyan la desigualdad, la marginación y la injusticia social, donde priven principios de honestidad, respeto y colaboración, en fin, que la humanidad se pueda insertar en un proceso evolutivo que en este momento se llama desarrollo sostenible. Para llegar a esta realidad es necesario iniciar en pequeñas comunidades con las que se pueda trabajar, pues en un mundo globalizado la acción local, casi imperceptible, puede llegar a ser mucho más poderosa de lo que se piensa. En este mundo donde se pretende homogeneizar la cultura y donde pareciera que ésta se desvanece, la identidad de los pueblos tiene que reforzarse; aunque parezca paradójico, lo único y lo múltiple pueden y deben coexistir. Una característica de la investiga-

${ }^{17}$ En esta etapa de la investigación se trabajó con el maestro Juan Campos Alanís, especialista en manejo de sistemas de información geográfica y planeación regional, actualmente adscrito a la facultad de Geografía de la UAEM. 
ción en que se basa el artículo y que la distingue de la mayoría de los trabajos que sólo se interesan por los aspectos teóricos o por los prácticos, es que trata ambos. Así se logra contrastar la teoría con la realidad en un proceso permanente (dialéctico) que permitirá reconstruir y mejorar la teoría y la práctica. Estamos de acuerdo en que los paradigmas actuales no son capaces de resolver una problemática ambiental que aún genera confusiones, pues aunque el término ambiente ha sido conceptualizado como la interacción entre la sociedad y la naturaleza; esto es, un sistema complejo, al referirse a sus problemas únicamente se mencionan los que afectan a la naturaleza y dejan de lado los que tienen que ver con la sociedad, de ahí que sea una visión parcial y, en este sentido, se afirma que mientras se continúe con este enfoque disciplinario, los problemas ambientales no se resolverán y, por tanto, tampoco será posible acceder al proceso de desarrollo sostenible. Por eso insistimos en aportar elementos para construir un paradigma que analice, comprenda y proponga soluciones realmente integrales a partir de la creación de nuevas categorías de análisis que, a su vez, nos dirijan hacia la construcción de paradigmas alternativos.

Ante estas consideraciones, la investigación se desarrolló en un ir y venir entre teorías y metodologías, pero que pensamos podían complementarse. Como se puede observar, el estilo de pensamiento que predomina se acerca a la postura dialéctica crítica, en el sentido de situar los hechos en un todo sociocultural (totalidad), de resaltar la interacción entre sujeto y objeto, de la dependencia entre el objeto y la forma de ser conocido; esta forma de conocer, a su vez, depende del contexto en el cual se desarrolla el sujeto y de la comunicación subjetiva que se establece en la sociedad (incluido el investigador) y, finalmente, porque busca transformar o construir una sociedad donde los individuos vivan mejor. Sin embargo, la totalidad a la que se refiere esta postura y otras teorías sociológicas, sólo consideran a la sociedad como sistema y dejan fuera, o tocan de manera superficial, al medio natural, a diferencia de este trabajo que considera una totalidad en la que se entrelazan la sociedad y la naturaleza como un sistema complejo único.

No cabe duda que proponer un marco teórico metodológico alternativo para el análisis ambiental, desde la perspectiva de los sistemas complejos y la sostenibilidad, es un reto que debe afrontarse mediante la integración de grupos interdisciplinarios que aporten conocimientos específicos de cada una de sus áreas; y 
consideramos que con esta investigación se da un acercamiento a esta visión integradora. Por otro lado, la sostenibilidad es una condición que sólo se puede evaluar a largo plazo, los resultados de las acciones realizadas en el presente tendrán efectos en el mediano y largo plazos, por ello es vital empezar a actuar ahora con los principios y criterios que permitan garantizar, dentro de la incertidumbre que caracteriza a los sistemas complejos, su cumplimiento a través de la planeación integrativa participante y continuar con las investigaciones específicas para identificar sus efectos.

En suma, el resultado final de la propuesta es contribuir a la construcción de un marco teórico-metodológico para analizar la problemática ambiental que ayude a satisfacer las necesidades de los habitantes de las comunidades, que permita mejorar su nivel de vida a través del empleo, mejoramiento y conservación del patrimonio natural y cultural, tendentes a procurar condiciones armónicas en su desarrollo. Para ello se proponen las siguientes categorías de análisis: hommoecosistema, aprovechamiento ambientalmente intuitivo racional, turismo armónico y planeación integrativa participante. Estas categorías se aplicaron en la elaboración del proyecto de turismo en San Miguel Almaya, Capulhuac, Estado de México, en el que se consideraron los intereses y conocimiento de diversos miembros de la comunidad, de representantes de la misma y de las autoridades de los tres ámbitos de gobierno; producto de ello se constituyó una cooperativa que a la fecha ha logrado apoyo para la limpieza de la laguna, un contrato con una asociación de deportes acuáticos, financiamiento de la secretaría del gobierno del estado y la incorporación de otras dos comunidades que conforman el Corredor Ecoturístico Almaya-Tlazala-Victoria. Como se comentó, el desarrollo sostenible no es una meta a alcanzar, sino un proceso de mejora permanente que se vive día a día, y que se considera ha iniciado en estas comunidades.

\section{Bibliografía}

Aguado-López, Eduardo y Rosario Rogel-Salazar (2005), "Los problemas teóricos y empíricos en la construcción del dato", en Antología del 1er. curso internacional de actualización de profesores sobre teorías y metodologías en ciencias sociales y humanidades: construcción de objetos de 
estudio interdisciplinario, México, Universidad Autónoma del Estado de México, mimeo, pp. 1-25.

Aguilar, Adrián G. (1994), "Ingreso y mercado laboral en ciudades turísticas", Ciudades, análisis de la coyuntura, teoría e historia urbana, 23, México, Red Nacional de Investigación Urbana (RNIU), pp. 10-17.

Arellano, Antonio (2000), "La guerra entre ciencias exactas y humanidades en el fin de siglo: el 'escándalo' Sokal y una propuesta pacificadora", Ciencia Ergo Sum, 7(1), Universidad Autónoma del Estado de México, México, pp. 56-66.

Barkin, David (1998), Riqueza, pobreza y desarrollo sostenible, México, Jus.

Barkin, David (2000), "Social tourism in rural communities: an instrument for promoting sustainable resources management”, ponencia presentada en la Latin American Studies Association, Miami, 16-18 de marzo, mimeo.

Barkin, David (2001), "Ecoturismo: del mito a la realidad", Derechos Humanos, órgano informativo de la Comisión de Derechos Humanos del Estado de México, México, pp. 101-102.

Beals, Ralph (1981), Introducción a la antropología, Aguilar, Madrid.

Bifani, Pablo (1999), "La relación hombre-naturaleza como fenómeno social", en La educación superior ante los desafíos de la sostenibilidad. Antología, vol. 1: En torno al desarrollo sostenible, Colección Biblioteca de la Educación Superior, ANUIES-Universidad de Guadalajara-Semarnap, México.

Blakely, Edward (1994), Planning local economic development, Theory and practice, sAgE Publications Oaks, California.

Blàzquez, S. M. et al. (2002), El tercer boom, indicadors de sostenibilitat del turisme de les Illes Balears 1989-1999, Centre d'Investigació Tecnologies Turístiques de les Illes Balears-Leonard Muntaner Editor, Islas Baleares. 
Blàzquez, S. M. et al. (2003), La mesura de la sostenibilitat del turisme a les Illes Balears, Universitat de les Illes BalearsCentre d'Investigació Tecnologies Turístiques de les Illes Balears, Islas Baleares, Govern de les Illes Balears-Conselleria de Turisme.

Borja, Jordi y Manuel Castells (2000), Local y global. La gestión de las ciudades en la era de la información, Taurus-UNCHS, México.

Brenner, Ludger (1999), "Modelo para la evaluación de la 'sostenibilidad' del turismo en México con base en el ejemplo de Ixtapa-Zihuatanejo", Investigaciones Geográficas, 39, Instituto de Geografía, Universidad Nacional Autónoma de México, México, pp. 139-157.

Capra, Fritjof (2002) La trama de la vida: una nueva perspectiva de los sistemas vivos, Anagrama, Barcelona.

César, Dáchary A., Stella M. Arnaiz B. y June Thomas (eds.) (2003), Turismo rural y economía local, Universidad de Guadalajara (México)-Universidad Nacional del Litoral (Argentina).

Chávez de la Peña, Jorge (2001), “¿A dónde llevan los excesos del ecoturismo?", Derechos Humanos, órgano informativo de la Comisión de Derechos Humanos del Estado de México, México, pp. 97-98.

Ellul, Anthony (2002), The Systemic and prospective sustainability analysis project within camp $<$ Malta $>$, Ministry for Economic Services, unEP, Plan Blue, Malta.

Farrell, Bryan H. y Louise Twining-Ward (2004), "Un nuevo concepto del turismo", Annals of Tourism Research, 6(1), UIB, Palma de Mallorca, pp. 65-90.

Freire, Paulo (2001), La educación como práctica de la libertad, Siglo xxi, México.

Fundación Friedrich Ebert (s.f.), Nuestro futuro común. Explicación al reporte Brundtland, un resumen, Fundación Friedrich Ebert, México. 
Galeano, Eduardo (2003), Las venas abiertas de América Latina, Siglo xxi, México.

Gallegos, Oswaldo y Álvaro López L. (2004), “Turismo y estructura territorial en Ciudad Juárez, México”, Investigaciones Geográficas, 53, Instituto de Geografía, Universidad Nacional Autónoma de México, México, pp. 141-162.

García, Ana (1979), Cancún: turismo y subdesarrollo regional, Universidad Nacional Autónoma de México, México.

García, Rolando (1986), “Conceptos básicos para el estudio de sistemas complejos", en E. Leff (coord.), Los problemas del conocimiento y la perspectiva ambiental del desarrollo, Siglo xxi, México, pp. 381-409.

García, Rolando (1988), Deterioro ambiental y pobreza en la abundancia productiva. El caso de la Comarca Lagunera, IFIAS-CINVESTAV, México.

García, Rolando (1994), "Interdisciplinariedad y sistemas complejos", en E. Leff (comp.), Ciencias sociales y formación ambiental, Gedisa-Universidad Nacional Autónoma de México, Barcelona.

Geertz, Clifford (1995), La interpretación de las culturas, Gedisa, Barcelona.

Gliessman, Stephen R. (2002), Agroecología: procesos ecológicos en agricultura sostenible, Turrialba, LITOCAT, Costa Rica.

Habermas, Jürgen (2001), Teoría de la acción comunicativa; racionalidad de la acción y racionalización social, t. I, $3^{\text {a }}$ ed., Taurus, Madrid.

Harris, Rob, Tony Griffin y Peter Williams (eds.) (2003), Sustainable Tourism a global perspective, Butterworth Heinemann, Londres.

Hughes, George (2002), "Indicadores medioambientales", Annals of Tourism Research, 4(1), Uів, Palma de Mallorca, pp. 163-185. 
Hunter, Colin (2003), "Aspects of the sustainable tourism debate from a natural resources perspective", en R. Harris, T. Griffin y P. Williams (eds.), Sustainable Tourism a global perspective, Butterworth Heinemann, Londres.

Jinyang, Deng, Brian King y Thomas A. Bauer (2002), "La evaluación de atractivos naturales para el turismo", Annals of Tourism Research, 4(1), uiB, Palma de Mallorca, pp. 144-162.

Kuhn, Thomas (1971), La estructura de las revoluciones científicas, Fondo de Cultura Económica, México.

Leff, Enrique (coord.) (1990), Medio ambiente y desarrollo en México, vol. I, Universidad Nacional Autónoma de México-Porrúa, México.

Leff, Enrique (comp.) (1994), Ciencias sociales y formación ambiental, Gedisa, Barcelona.

Leff, Enrique (2000), La complejidad ambiental, Siglo XXI, México.

Leff, Enrique (2002), Saber ambiental, sostenibilidad, racionalidad, complejidad, poder, Siglo xxi, México.

Leiper, Neil (1979), “The framework of tourism. Towards a definition of tourism, tourist, and the tourist Industry", Annals of Tourism Research, octubre-diciembre, UIB, pp. 390-407.

Leis, Héctor Ricardo (2001), La modernidad insostenible, Nordan-PNuma (Colección Pensamiento Ambiental Latinoamericano 2), Montevideo.

Luhmann, Niklas (1998), Sistemas sociales: lineamientos para una teoría general, Anthropos, Barcelona.

Lyotard, J.-F. (1999), La posmodernidad explicada para niños, Gedisa, Barcelona.

Martínez-Figueroa, Luis A. (2003), "Turismo rural. Nuevos empresarios para un mundo tradicional”, en César Dáchary A., Stella M. Arnaiz B. y June Thomas (eds.) (2003), Tu- 
rismo rural y economía local, Universidad de Guadalajara (México)-Universidad Nacional del Litoral, Argentina, pp. 62-85.

Martínez, Miguel (1997), El paradigma emergente, Trillas, México.

Masera, Omar, Marta Astier y Santiago López-Ridaura (1999), Sostenibilidad y manejo de recursos naturales. El marco de evaluación MESMIS, Mundi-Prensa-Gira-Instituto de Ecología-Universidad Nacional Autónoma de México, México.

Mombrú, Andrés (2005), “¿Modernidad o hipermodernidad?, Educar-Argentina, en <www.educar-argentina.com.ar/jul/ $2005>, 9$ de octubre.

Morin, Edgar (2001), Introducción al pensamiento complejo, Gedisa, Barcelona.

Morin, Edgar (2004), El método. t. v. La humanidad de la humanidad, Cátedra, Madrid.

OMT (Organización Mundial de Turismo) (1999a), Agenda para planificadores locales: turismo sostenible y gestión municipal, OMT, Madrid.

OMT (1999b), Guía para administraciones locales: desarrollo turístico sostenible, OMT, Madrid.

OMT (1998a) El nacimiento del tiempo, Tusquets Editores, Barcelona.

OMT (1998b) “¿El fin de la ciencia?”, en Fried Schnitman (ed.), Nuevos paradigmas, cultura y subjetividad, Paidós, México, pp. 37-60.

OMT (1998c) "De los relojes a las nubes", en Fried Schnitman (ed.), Nuevos paradigmas, cultura y subjetividad, Paidós, México, pp. 395-413.

OMT (2002), Le tourism et la réduction de la pauvreté, Madrid, Organization Mondiale du Touris, (OMT). 
ONU (Organización de Naciones Unidas) (2000), Declaración sobre derechos humanos, en <www.ohchr.org/spanish>, 11 de abril de 2006.

ONU (2005), Informe sobre desarrollo humano, en <www.hdr.undp. org/reports/global/2005/spanol/pdf>, 10 de junio de 2006.

Osorio, Isabel (1994), "Impactos del turismo sobre la desigualdad social", Ciudades, análisis de la coyuntura, teoría e historia urbana, 23, Red Nacional de Investigación Urbana (RNIU), México, pp. 31-38.

Osorio, Maribel (2004), "El análisis del turismo desde la perspectiva de los sistemas funcionales", en Memorias Coloquio de Investigación 2004, Universidad Autónoma del Estado de México, México, pp. 29-33.

Prigogine, Ilya (1983), La nueva alianza. Metamorfosis de la ciencia, Alianza, Madrid.

Prigogine, Ilya (1998a), El nacimiento del tiempo, Tusquets, Barcelona.

Prigogine, Ilya (1998b), “¿El fin de la ciencia?”, en Fried Schnitman (ed.), Nuevos paradigmas, cultura y subjetividad, Paidós, México, pp. 37-60.

Prigogine, Ilya (1998c), "De los relojes a las nubes", en Fried Schnitman, Nuevos paradigmas, cultura y subjetividad, Paidós, México, pp. 395-413.

Ramírez-Velázquez, Blanca R. (2003), Modernidad, posmodernidad, globalización y territorio. Un recorrido por los campos de las teorías, Universidad Autónoma MetropolitanaXochimilco, México.

Sebastián, Luis de (1997), Neoliberalismo. Apuntes críticos de economía internacional global, Trotta, Madrid.

Semarnap-INEgi (1998), Estadísticas del medio ambiente México, 1997, Secretaría de Medio Ambiente, Recursos Naturales y Pesca-Inegi, México. 
Semarnat (2003), Información sobre incendios forestales, Coordinación de Incendios Estatales, Secretaría de Medio Ambiente y Recursos Naturales, delegación Estado de México, mimeo, México.

Sectur (Secretaría de Turismo) (2000), Politica y estrategia nacional para el desarrollo turístico sostenible, Secretaría de Turismo, México.

Sectur (2004), Cómo desarrollar proyectos de ecoturismo, Secretaría de Turismo, México.

Serrano Barquín, Rocío y Marita Morales (2002), “Turismo sostenible y desarrollo local en áreas silvícolas”, El Periplo Sostenible, 8, en <www.uaemex.mx/plin/psus/rev8/e05. html>, 21 de mayo de 2006.

Serrano-Barquín, Rocío (2006), "Desarrollo, sostenibilidad y turismo en una comunidad lacustre del Valle de Toluca; caso: San Miguel Almaya, Estado de México”, tesis doctoral, Universidad Autónoma del Estado de México, México.

Steward, J. (1977), Evolution and Ecology, University of Illinois Press, Illinois.

Tetreault, Darcy (2004), "Una taxonomía de modelos de desarrollo sostenible", Espiral, x(29), Universidad de Guadalajara, México, pp. 45-77.

Toledo, V. M. (1989), "La perspectiva etnoecológica: cinco reflexiones sobre las 'ciencias campesinas', sobre la naturaleza con especial referencia a México", en Maihold y Meza (comps.), Ecología: motivo de solidaridad, Fundación Friedrich Ebert, México.

Touraine, Alain (1994), Crítica de la modernidad, Fondo de Cultura Económica, México.

UNEP (United Nation Environmental Programm) (2002), Perspectiva del Medio Ambiente Mundial-3 (PMAM-3), en <geo.unepwcmc.org/presssesp.htm>, 23 de marzo de 2005. 
Vattimo, Gianni (1990), La sociedad transparente, Paidós, Barcelona.

Wallerstein, Immanuel (1997), Abrir las ciencias sociales, Universidad Nacional Autónoma de México-Siglo xxi, México.

WTO (World Tourism Organization) (1994), National and regional tourism planning. Methodologies and case studies, WTO, Madrid.

WTO (2002), Enhancing the economic benefits of tourism for local communities and poverty alleviation, wTO, Madrid.

www.cinu.org.mx/temas/des_sus, 21 de abril de 2006.

www.unep.org/geo/geo3/spanish/overview, 25 de febrero de 2006.

Recibido: 20 de septiembre de 2005. Reenviado: 17 de enero de 2007. Aceptado: 21 de enero de 2007.

Rocío del Carmen Serrano Barquín. Es doctora en ciencias ambientales por la Facultad de Química de la Universidad Autónoma del Estado de México (UAEM). Realizó estudios de licenciatura en geografía y maestría en planeación urbana y regional en la misma universidad. Actualmente es directora de la revista virtual El Periplo Sostenible y encargada del despacho del Centro de Investigación y Estudios Turísticos (Cietur) de la Facultad de Turismo de la UAEM. Su línea de investigación actual es estudios ambientales del turismo. Algunas de sus publicaciones son: "Turismo sostenible y desarrollo local en el sur del Valle de Toluca”, en Fernández et al. (eds.), Turismo y transformaciones urbanas en el siglo XXI, Universidad de Almería, España, pp. 338-344, (2002); "El turismo rural como alternativa de desarrollo local en Santa María Jajalpa, en el Estado de México, en VII Seminario Internacional. Red Iberoamericana de Investigadores sobre globalización y territorio, Universidad de Camagüey, Cuba, pp. 1-12, (2002); "Estudios ambientales del turismo", en G. M. Osorio y M. Castillo (coords.), Ensayos teórico-metodológicos: cuatro enfoques, México, UAEM, pp. 45-57 (2006); en coautoría, “Ideología ambiental y educación”, Educere, Venezuela (en prensa). 